\title{
«Свет без пламени»: Лестница Якова Л. Улицкой и Доктор Живаго Б. Пастернака
}

\author{
TÜNDE SZABÓ \\ Pécsi Tudományegyetem Szláv Filológia Tanszék, H-7624 Pécs, Ifjúság útja 6. \\ E-mail: sztunde1512@gmail.com
}

(Received: 16 September 2019; accepted: 24 November 2019)

Людмила Улицкая не раз отмечала, что творчество Бориса Пастернака оказало огромное влияние на ее мировоззрение. Вспоминая процесс формирования своих взглядов на мир, в сборнике эссе Священный мусор она ставит рядом два основополагающих для нее духовных источника - научный и художественный: «скромное открытие о кружевной природе человеческого бытия, о тайне, заключенной не только в узелках, но и в пробелах между ними, я сделала в студенческие годы. В то время я была студентом-генетиком и переживала великое открытие века, которое кое-как добралось до затравленной советской властью биологической науки. Я имею в виду двойную спираль ДНК Уотсона и Крика. [...] Но кроме этих двух нобелевских лауреатов был еще и третий, ночной, встреча с которым меня потрясла никак не меньше. Это был Борис Пастернак, вернее, его роман Доктор Живаго... Этот роман, уже в первом к нему прикосновении, открыл для меня это кружево жизни. Впоследствии я много раз его перечитывала и находила в нем все новые и новые драгоценности. [...] Именно Пастернак снял с моих глаз пленку, и я стала видеть благодаря ему то, о чем прежде и не догадывалась: о связи всего со всем, о невысказуемой красоте этой связи» (УлицкАя 2012: 55-56, 58).

Эпизод знакомства с романом Доктор Живаго был запечатлен в сюжете романа Улицкой Зеленьй шатер, где один из героев, преподаватель русской литературы Виктор Юльевич Шенгели втайне читает рукописный экземпляр романа Пастернака. В его восприятии «это было продолжение той русской литературы, которая казалась ему полностью завершенной, совершенной и всеобъемлющей. Оказалось, что эта литература дала еще один побег, современный» (УЛИцКАЯ 2015: 107, 108).

Связь между двумя произведениями была отмечена в критической литературе. О. Ю. Осьмухина выделяет несколько параллельных черт, таких, как например, тенденция к эпопеизации: «как и в Докторе Живаго, в Зеленом шатре представлена попытка проследить развитие русского этноса определенной эпохи в общей перспективе отечественной истории в рамках крупного жанрового образования» (Осьмухина 2013: 206); скрещение судеб разных персонажей: «Вполне обозримые параллели с пастернаковским текстом 
прослеживаются на протяжении всего Зеленого шатра. Это касается не только „незримых скрещений“ судеб главных и второстепенных героев, но [...] и эпиграфа к роману, являющегося отрывком из письма Б. Пастернака к В. Шаламову» (Осьмухина 2013: 207); и тема преодоления смерти и единства личности: «Очевидно, что многие сюжетные переплетения мытарства человека в поисках себя и собственного места в мире в романе Доктора Живаго отразятся и в тексте Л. Улицкой» (Осьмухина 2013: 208).

Все перечисленные особенности поэтики романа Пастернака можно отнести и к роману Улицкой Лестница Якова, его связь с Доктором Живаго на уровне макроструктур очевидна. Хронотоп произведения Улицкой также эпопейный, поскольку сюжет охватывает ровно сто лет: с 1911 по 2011 гг., а герои романа оказываются не только в разных уголках России, но и за рубежом. Главный герой Яков Осецкий родом из Киева, работает в Москве, а как репрессированный пребывает определенные сроки в разных местах - в Сталинграде, в Бийске, в Абезьском лагере, в Калинине. Главная героиня Нора живет в Москве, но ездит на Алтай, в Грузию и в Америку. Тем не менее, как и в романе Пастернака, центром событий и пересечения судеб героев является Москва. Поэтому и текст Улицкой можно причислить к так называемому «московскому тексту» русской литературы. Но тогда как «Пастернак создает в своем творчестве мифопоэтический вариант „московского текста“, в котором исторические реалии просвечиваются архетипическими моделями культуры〉 (СЕлЕМЕневА 2009: 26), в романе Улицкой образ Москвы связан с классической русской культурой, прежде всего с культурой Серебряного века.

Характерной чертой обоих романов является также автобиографичность. Как отмечает Д. Быков, «в 1947 году Пастернак понял то, над чем бился двадцать лет: сюжетом книги должна была стать его собственная жизнь, какой он хотел бы ее видеть» (Быков 2010: 723). Образ главной героини романа Улицкой Норы тоже во многом автобиографичен: и дата рождения, и место жительства, и проблемы сына, и работа в театре указывают на биографию самого автора. Образ же ее деда Якова создан на основе рукописных источников записных книжек и семейной переписки деда Улицкой (УлицкАя 2017). Личная судьба героев в обоих романах тесно связана с историей страны. Судьба Юрия Живаго во многом определена революциями и гражданской войной, а в романе Улицкой главные исторические события XX в. служат не только фоном, но также оказывают сильное воздействие на судьбы героев. Акцентируется в этом плане жизненный путь Якова, который представляет собой взлеты и падения в зависимости от общественно-исторических событий и от беспрерывной в любых обстоятельствах творческой деятельности героя.

В романе Пастернака важное место занимает проблема личности и «стадности», историософская интерпретация которой дается дядей Юрия Живаго Николаем Веденяпиным: «Всякая стадность - прибежище неодаренности, все равно верность ли это Соловьеву, или Канту, или Марксу. Истину ищут только одиночки и порывают со всеми, кто любит ее недостаточно» (ПАСтЕРНАК 1994: 12). В романе Улицкой эта проблема представлена как конфликт 
разных ментальностей - интеллектуала Серебряного века и homo sovieticus в пределах одной семьи. Яков яркая личность, он всегда предпочитает индивидуальность стадности. Объясняясь с Марусей по поводу нелегального кружка марксистов, он говорит: «ценность индивидуального существования, свободу личности [Маркс] подчинял идеалам этого самого справедливого будущего общества. Но мне кажется, что здесь возможно такое подавление личности, подчинение интересов индивидуума общественным интересам, что меня это смущает. [...] Да и зачем этот кружок? Групповые занятия всегда приводят к лишней трате времени, я в этом убедился» (УлицКАЯ 2015: 217). Сын же Якова Генрих - представитель «нового», советского человека, обреченный на стадность еще с детства. В десятилетнем возрасте его увлекло планерство, и в тот же момент «произошло его стихийное отречение от индивидуального пути, которым были так озабочены его родители. Он впервые почувствовал счастье слияния с массами, единочувствие с окружающим миром...» (У лицКАя 2015: 501). Колебание Маруси между двумя ментальностями - индивидуализмом и коллективностью - отражается и в их семейных отношениях: со временем у нее сложится более близкое отношение с сыном, чем с Яковом, и изменяет мужу профессором марксизма-ленинизма, старым знакомым Иваном Белоусовым.

Индивидуалист Яков представляет собой интеллигента начала XX века. Он экономист по образованию, но серьезно занимается музыкой, создает оригинальные работы в самых разных сферах культуры, собирается писать художественную прозу. Его житейские испытания и поиски близки судьбе Юрия Живаго, врача и поэта, а некоторые моменты сближают его и с биографией самого Пастернака. ${ }^{1}$ Глубинная связь романа Улицкой с романом Пастернака, однако, создается, на наш взгляд, не с помощью сюжетной линии жизни Якова, а через образ Норы.

Нора, внучка Якова, наследница его таланта и ментальности - театральный художник. Она работает над постановками разных произведений русской и мировой литературы, процесс создания которых занимает значительную часть ее сюжетной линии. Именно изображение процесса формирования постановок Норы и прием встраивания произведений другого вида искусства в текст романа придает своеобразие произведению Улицкой и сближает его

${ }^{1}$ Хочется обратить внимание лишь на один момент этой параллели. В старости Яков Осецкий страдает от больной ноги: «Второй год, с тех пор как левая нога отказала и ходить он мог только с костылем, он жил в Абези» (УлицКАЯ 2015: 678). «Акцент на ноге» у Пастернака входит в тот «автобиографический пучок, ретроспективно мифологизированный самим Пастернаком, а позднее и его братом», который исследователями обозначен как «комплекс Иакова» (Жолковский 2011: 92). В поэтической практике Пастернака этот «комплекс» реализуется как «экстаз поражения, неотличимого от победы» (Жолковский 2011: 93). Прототипом «комплекса» послужила ветхозаветная история о Иакове, о его ночной борьбе с Богом: «говорил он, я видел Бога лицом к лицу, и сохранилась душа моя» (Бытие 32: 30). Итог судьбы Якова Осецкого - тот же самый «экстаз поражения, неотличимого от победы», характерный и для других главных героев в романах Улицкой (например, для Даниэля Штейна или Павла Кукоцкого). 
больше всего с Доктором Живаго, романом «о том, как живут стихом и как стихи рождаются из жизни» (Вознесенский 1990: 226). Кроме того, в Лестнице Якова появляются прямые ссылки на определенные стихотворения из тетради Живаго, символика которых оказывается основополагающей в произведении Улицкой.

Большинство стихов живаговского цикла было написано Пастернаком до начала и во время работы над романом. С некоторыми из них читатели были знакомы как с самостоятельными произведениями. Одно из наиболее популярных стихотворений Пастернака-Живаго - это пятнадцатое стихотворение в цикле Зимняя ночь. Написанное в 1946 году, оно вошло в Избранное поэта 1948 года, сыграв потом важную роль во взаимосвязи живаговского стихотворного цикла и всего романа. ${ }^{2}$

С помощью рефренной строки стихотворения «Свеча горела на столе, свеча горела» связаны между собой две ключевые ситуации сюжета романа. Первая ситуация - это пробуждение творческого начала в Юрии Живаго, момент, когда молодой доктор по пути к Свентицким на елку проезжает по Камергерскому переулку мимо дома, где снимает комнату Паша Антипов. Внимание Живаго привлекает свеча в окне, за которым в это же время происходит объяснение Лары со своим будущим мужем. Именно в этот момент рождается упомянутая строка Зимней ночи: «,Свеча горела на столе. Свеча горела..." - шептал Юра про себя начало чего-то смутного, неоформившегося, в надежде, что продолжение придет само собой, без принуждения. Оно не приходиЛО» (ПАСТЕРНАК 1994: 66).

Вторая ситуация связана с концом сюжета, когда в той же самой комнате оплакивает умершего Живаго случайно попавшая туда Лара. Она напрягает память, «чтобы восстановить тот рождественский разговор с Пашенькой, но ничего не могла припомнить, кроме свечки, горевшей на подоконнике, и протаявшего около нее кружка в ледяной коре стекла. Могла ли она думать, что лежавший тут на столе умерший видел этот глазок проездом с улицы и обратил на свечу внимание? Что с этого, увиденного снаружи пламени, - „Свеча горела на столе, свеча горела“, - пошло в его жизни его предназначение?» (ПАСТЕРНАК 1994: 403).

Свеча, таким образом, является, с одной стороны, сигналом «скрещения судеб» главных героев, замыкающим круг в композиции сюжета. С другой стороны, она становится не только символом любви и смерти, но и символом бессмертия, залог которого - художественное творчество героя. ${ }^{3}$

Преодоление смерти с помощью художественного творчества подчеркивается и в романе Улицкой, а именно, когда в конце сюжета цитируется эта

${ }^{2}$ См. комментарии к роману: «Зажженная свеча - центральный символический образ романа Доктор Живаго. „Свеча горела““ - было одним из предполагаемых его названий...» (ПАСТЕРНАК 1994: 520).

${ }^{3}$ Не следует забывать и о том, что Лара называет свечой самого Живаго: «А ты все горишь и теплишься, свечечка моя ярая! - влажным, заложенным от спанья шепотом тихо сказала она» (ПАСТЕРНАК 1994: 353).

Studia Slavica Hung. 64, 2019 
же рефренная строка Зимней ночи. Нора, ознакомившись с архивными материалами КГБ о деле деда Якова, потрясенная информацией о поступке его сына (и своего отца) Генриха, отправляется домой. «По Дмитровке прошла мимо Камергерского переулка, мимо углового дома, описанного Пастернаком. Того, где „свеча горела на столе, свеча горела“... Антипов снимал тут квартиру, а Юрий Андреевич Живаго, в кружеве еще не свершившейся судьбы, проезжая мимо, приметил этот ничего не значащий огонек в одном из окон и оставил его в литературной вечности» (УлицкАя 2015: 718). Судьба немолодой уже героини Улицкой к этому моменту почти свершилась: после постоянной спешки и любовных бурь она пришла в «тихую и вполне осмысленную точку» (У лицКАя 2015: 702). Нора собирается «свести концы с концами» - и запечатлеть образ своего деда в вечности: «а может, разложит старые письма и напишет книжку... Такую книжку... которую дед то ли не успел написать, то ли сожгли во внутреннем дворе Внутренней тюрьмы на Люблянке...» (УлицкАя 2015: 721). Сюжет завершается размышлениями Норы о том, кто именно ее главный герой.

Пробуждение в Норе нового творческого - писательского - начала, таким образом, закодировано в романе Улицкой с помощью ссылки на параллельную ситуацию в романе Пастернака и также на стихотворение, родившееся в этой ситуации и вошедшее потом в цикл стихов, созданных Живаго.

Оставив Камергерский переулок позади и продолжая свой путь домой, Нора заходит в храм Космы и Дамиана. Там она под влиянием церковного пения заплачет, ${ }^{4}$ вспоминая поступок своего отца и в конце концов прощая его. При выходе из церкви, в наррации фиксируется время происходящего: «Это был канун Преображения Господня. „Обыкновенно свет без пламени исходит в этот день с Фавора...“ Да, да, конечно. Свет без пламени... Свет уже померк, но праздник еще не кончился...» (УлицкАя 2015: 719). Вскоре после этого, когда Нора уже входит в свой дом, обозначение времени превращается в описание окрестности: «Стемнело, но свет без пламени все еще теплился в небе» (УлицКАя 2015: 721).

Отмеченное кавычками в нарраторском тексте предложение «Обыкновенно свет без пламени исходит в этот день с Фавора...»- это цитата из другого, четырнадцатого по порядку в цикле Живаго стихотворения Aвгу cm. Оно было написано в 1953 г. и его принято считать «самым пастернаковским стихотворением» цикла, одновременно его смысловым центром (ВлАсов 2004). В нем лирический герой вспоминает сон, в котором ему снились собственные похороны. На этих похоронах он услышал свой «провидческий» голос,

4 Эта сцена напоминает характеристику Лары в церкви. «Лара не была религиозна. В обряды она не верила. Но иногда для того, чтобы вынести жизнь, требовалось, чтобы она шла в сопровождении некоторой внутренней музыки. Такую музыку нельзя было сочинять для каждого раза самой. Этой музыкой было слово Божие о жизни, и плакать над ним Лара ходила в церковь» (ПАСтЕРНАК 1994: 42). «Неожиданно Нора заплакала. Она вовсе не была религиозной, православие к ней никакого отношения не имело, как и все другие религии. Но сердце отозвалось на звуки. Бог мой!» (УлицКАя 2015: 719). 
прощавшийся, среди прочего, «с творчеством и чудотворством». В стихотворении названа точная дата приснившегося - 6 августа, праздник Преображения Господня. Выделенная в романе Улицкой строка стихотворения восходит к первообразу христианского праздника, к библейскому сюжету преображения Христа перед тремя учениками на горе Фавор, где «просияло лице Его, как солнце, одежды же Его сделались белыми, как свет» (Матвей 17: 2).

Рождение стихотворения Август в сюжете романа Пастернака не описано, но его последняя строка явно перекликается с эпизодом из главы Лесное воинство. В партизанском лагере Живаго лежит один в лесу, и пестрые пятна солнца покрывают его тело «клетчатым узором» и он размышляет о «творении, твари, творчестве и притворстве» (ПАСТЕРНАК 1994: 275).

Кроме этой переклички с сюжетом романа, стихотворение Август имеет существенную для всего творчества Пастернака автобиографическую основу (ФЛЕйшмАН 1977). Оно было написано в пятидесятилетие несчастного случая, когда Пастернак еще ребенком упал с лошади и сломал правую ногу. По его воспоминаниям, очнувшись в гипсе «впервые открыл для себя, что слова тоже могут подчиняться музыкальному ритму. Это было его преображением - он проснулся поэтом и музыкантом» (Быков 2010: 26). Поскольку это произошло 6 августа, Преображение в его мышлении и художественном творчестве стало не только символом проявления божественного начала в имманентном мире, но и символом рождения поэта и поэтического творчества.

Так, в двух процитированных в романе Улицкой стихотворениях живаговского цикла и в соответствующих эпизодах романа Пастернака смысловой центр составляет художественное творчество, его непосредственная связь с любовью и смертью, с одной стороны, и с проявлением божественного начала в имманентном мире, с другой. ${ }^{5}$ Общим символом этих связей является «свет без пламени» как сигнал Преображения Христа.

В романе Улицкой при свете без пламени завершается жизненный путь героини. Только теперь она знакомится с содержанием семейного архива, который получила в самом начале сюжета, и, таким образом, замыкается круг в композиционном плане. Тут же происходит ее преображение в писателя создателя того же романа, героем которого является она. В ее последних размышлениях о человеческой сущности стирается граница между собственным голосом и голосом повествователя. «Яков! Яков! Эту книгу ты хотел написать и не написал?» (У лицкАя 2015: 722) - обращается к деду Нора-повествователь. Если учесть и автобиографические черты образа Норы, то можно утверждать, что она настолько же близка Улицкой, автору романа, насколько образ Юрия Живаго близок Пастернаку.

${ }^{5}$ Как считает Н. Фатеева, «за его [Пастернака - Т. С.] стихотворными и прозаическими текстами стоит некоторый инвариантный код смыслопорождения, который делает их взаимопереводимыми на глубинном семантическом уровне. Это, в свою очередь, говорит о том, что, несмотря на вариативность форм выражения, сохраняется единство языковой творческой личности» (ФАТЕЕВА 2003: 10).

Studia Slavica Hung. 64, 2019 
«Свет без пламени» появляется не только в конце сюжета романа Улицкой, но еще намного раньше, в одной из постановок, над которой Нора работает с Тенгизом. В 1981 году Тенгиз предлагает Норе ставить трагедию Шекспира Король Лир. Для интерпретации пьесы он выделяет фразу Лира, произнесенную шекспировским героем в кульминационный момент действия, во время бури: «Неприкрашенный человек - и есть это бедное голое двуногое животное. И больше ничего! Долой, долой с себя все лишнее!» (УлицкАя 2015: 200). Тенгиз цитирует фразу сначала по-английски, а потом и в русском переводе. Примечательно, что вскоре после этого эту же фразу выделяет Яков в письме к Марусе от 1912 года. Прочитав драму, Яков оценивает ее имеющиеся в то время русские переводы. «Язык Шекспира архаический, пришлось сделать glossary, но разница с русскими переводами огромная! В этом сравнении нахожу огромное удовольствие» (УлицКАя 2015: $241)$ - пишет он, и предлагает даже свой вариант перевода фразы Лира.

В романе Улицкой высказывание Лира выполняет, таким образом, несколько функций. Во-первых, оно выступает как связующий элемент между двумя сюжетными линиями - Норы и Якова. Несмотря на огромное количество произведений, упоминаемых двумя героями, именно Король Лир является тем единственным произведением, с которым имеют дело они оба. Вовторых, для Норы и Тенгиза фраза шекспировского героя служит поводом для осмысления собственной жизненной ситуации: «Знала она [Нора - Т. С.] этот текст. Прекрасно знала. Но тут вдруг эти слова - „долой все лишнее“показались безумно важными для нее лично» (УлицкАя 2015: 200). В-третьих, посредством вопроса о переводе драмы Шекспира в сюжет романа Улицкой вводится пастернаковский подтекст.

Как известно, в период работы над романом Доктор Живаго Пастернак интенсивно занимался переводом драм Шекспира. Самым знаменитым в его переводе стал Гамлет, главный герой которого получил свое отражение в первом, одноименном стихотворении цикла Живаго. В 1949 г. Пастернак перевел и драму Король Лир. Он характеризовал ее как «тихую трагедию», в которой подвергается преследованию «любовь дочерняя и, в более широком смысле, любовь к ближнему, любовь к правде» (ПАСтерНАК 1990: 190).

Тенгиз цитирует фразу Лира в переводе Пастернака, а в интерпретации сцены бури Нора опирается на важный и для романа Доктор Живаго источник: на философию Н. Бердяева. В оформлении сцены бури Нора непосредственно использует идею Бердяева об одухотворенности природы: «У него изложено было на языке сложном, но если упростить до нужного Норе уровня, - вся материя одухотворена. [...] Что очень важно для нашей истории, потому что буря в Лире - бунт одухотворенной природы: воды, ветра, огня» (УлицкАя 2015: 208). Некоторые идеи Бердяева были близки и Пастернаку. Существует предположение, что прототипом Веденяпина в Докторе Живаго послужил именно Бердяев (ВАнчугов 2015). Несмотря на то, что в романе Пастернака на первый план выступает учение философа об истории, большое значение имеют и его мысли о природе, любви, творчестве и христианстве. 
Исходной точкой интерпретации Норой последней сцены Короля Лира служит именно христианская антропология Бердяева, его идея о двойственной - материальной и божественной - природе человека. Божественную природу «неприкрашенного», голого человека - Лира с Корделией - Нора осмысляет с помощью символики Преображения. Ее эскиз для этой сцены воспроизводит канонические элементы иконы «Преображение». Сопровождающие Лира персонажи уподобляются ученикам Христа, и в картине Норы, также как и в иконописной традиции, главное значение придается несотворенному божественному свету, который исходит от Христа и который ослепляет его учеников. «Эдгар, Шут, Кент смотрят на них снизу, как ученики Христа в момент его Преображения. Свет нестерпимый. Скалы начинают светиться...» (УЛИцКАЯ 2015: 210).

Воспроизведение в эскизе Норы элементов Преображения на основе христианской иконописной традиции перекликается с упомянутым выше эпизодом конца сюжета романа, где момент Преображения Господня появляется в преломлении романа Пастернака, прежде всего двух стихотворений живаговского цикла. ${ }^{6}$ Меняется при этом статус героини. В 1981 г. Нора выступает как театральный художник. Визуализация последней сцены драмы Шекспира - это ее художественное видение, в котором она как один из героев романа дает определенный ответ на вопрос о сущности человеческой природы. Двадцать лет спустя, в 2011 г. Нора преображается сама - в итоге прожитой жизни и осмысления жизненного опыта своего деда и отца, она размышляет о сущности человека уже не как героиня романа, а как его автор-повествователь. В ее представлении сущность человека имеет двойственный характер. С одной стороны, эта сущность проявляется в потоке рода человеческого, в котором существование индивида не имеет большого значения. С другой стороны, это божественная природа отдельной личности, которая раскрывается прежде всего в любви и творческой деятельности.

На основе высказанных выше наблюдений интертекстуальная связь романа Л. Улицкой Лестница Якова и романа Б. Пастернака Доктор Живаго представляется нам несомненной. Она разворачивается как сложная система, охватывающая разные уровни произведения Улицкой. Кроме отдельных общих черт макроструктуры, важнейшую роль играют ссылки на два центральные стихотворения в цикле Живаго. Их символика сводится к доминантной роли художественного творчества, ${ }^{7}$ его взаимосвязи с любовью, смертью и бессмертием, которая получила дальнейшую интерпретацию в романе Людмилы Улицкой.

${ }^{6} \mathrm{Cp}$ :: «В пастернаковедении сложился стереотип: христианские мотивы вошли в творчество Пастернака одновременно с работой над романом Доктор Живаго. В действительности, уже в 1908 году Б. Л. Пастернак увлекся философией и религией» (ДАнилкинА 2015: 16).

${ }^{7}$ Ср.: «В художественном сознании Пастернака творчество, выводящее мир из состояния хаоса и помогающее ему перейти в состояние космоса, не есть одноактная деятельность созидания или пересозидания мира как в романтических философиях творчества, а длительный, многоэтапный процесс» (ХАН 2015: 17). 


\section{Литература}

Быков $2010=$ Быков Д. Борис Пастернак. Москва: «Молодая гвардия», 2010.

ВАнчУгов 2015 = ВАнчугов В. Философский герой «Доктора Живаго». Русская!dea, 10.02.2015. https://politconservatism.ru/prognosis/filosofskiy-geroy-doktora-zhivago.

ВлАсов $2004=$ ВлАсов А. С. Дар живого духа. Стихотворения Б. Пастернака «Август» и «Разлука» в контексте романа «Доктор Живаго». Bonpocы литературы 2004/5: 216-238.

ВОЗНЕСЕНСКИЙ 1990 = ВОЗНЕСЕНСКИЙ А. Свеча и метеЛь. В кн.: БАХНОВ Л. В. и др. (сост.) С разных точек зрения: «Доктор Живаго» Бориса Пастернака. Москва: «Советский писатель», 1990. 226-230.

ДАнилкинА 2015 = ДАнилкинА Т. В. Борис Пастернак и философия. Известия Тульского государственного университета 2015/2: 13-20.

Жолковский 2011 = Жолковский А. Поэтика Пастернака. Инварианты, структуpbl, интертекстыл. Москва: «Новое литературное обозрение», 2011.

ОсьмухинА 2013 = ОсьмухинА О. Ю. «Доктор Живаго» Б. Пастернака и «Зеленый шатер» Л. Улицкой: переосмысление традиции лирической эпопеи. Филология $u$ культура 2013/3: 206-209.

ПАСТЕРНАК 1990 = ПАСТЕРНАК Б. Замечания к переводам из Шекспира. В кн.: Борис Пастернак об искусстве. Москва: «Искусство», 1990. 175-192.

ПАСТЕРНАК 1994 = ПАСТЕРНАК Б. Доктор Живаго. Москва: «Тройка», 1994.

СЕЛЕМЕНЕВА $2009=$ СЕЛЕМЕНЕВА М. В. «Московский текст» в русской литературе ХХ века (на материале художественной прозы 1910-1950-х гг.). Вестник Российского университета дружбы народов 2009/2: 20-27.

УЛИЦКАЯ 2011 = УЛИцКАЯ Л. Зеленый шатер. Москва: «АСТ», 2011.

УЛИЦКАЯ 2012 = УЛИЦКАЯ Л. Священный мусор. Москва: «Астрель», 2012.

УЛИЦКАЯ 2015 = УЛИцКАЯ Л. Лестнища Якова. Москва: «АСТ», 2015.

УЛИцКАЯ $2017=$ УЛИЦКАЯ Л. «Лестница Якова» - «вынужденный» роман. https://ok. ru/video/246650507757.

ФаТЕЕВА 2003 = ФаТЕЕВА Н. А. Поэт и проза. Книга о Пастернаке. Москва: «Новое литературное обозрение», 2003.

ФЛЕЙШМАН 1977 = ФЛЕЙШМАН Л. Автобиографическое и «Август» Пастернака. Slavica Hierosolymitana 1977/1: 194-198.

ХАН 2015 = ХАН А. Творчество Бориса Пастернака в контексте эстетической и философской мысли ХХ века. (Acta Universitatis Szegediensis. Dissertationes Slavicae. Sectio Historiae Litterarum XXV.) Szeged: JATE Press, 2015.

\section{TÜNDE SZABÓ}

Department of Slavic Philology, Faculty of Humanities, University of Pécs

\section{Ulitskaya's Jacob's Ladder and Pasternak's Doctor Zhivago}

In her interviews and essays, Ulitskaya has often alluded to the great effect that Pasternak's poetry, and especially Doctor Zhivago, has had on her. In one of the episodes of her novel The Big Green Tent, she describes a first encounter with Pasternak's novel; the teacher of literature who plays a decisive role in the lives of the main characters reads a manuscript copy of the novel and describes it as a worthy continuation of 19th-century Russian prose. 
The parallels between the novels The Big Green Tent and Doctor Zhivago have already been the subject of scholarly attention but the connection between Jacob's Ladder and the Pasternak novel has not been studied so far. In this study, I examine this connection: on the one hand, at the level of macrostructures, the chronotope, the patterns of the heroes' fates and the principal thematic elements, and on the other hand, at the level of certain microstructures.

The latter are linked to the present-day plot of Ulitskaya's novel and, more specifically, Nora's life. Nora reads the correspondence and notes that her grandfather left for her as well as the KGB documents about Yakov Osetsky towards the end of her life (and the plot itself). As a result of this, she wishes to write the novel that her grandfather Yakov could not due to the historical situation.

The process of Nora's confrontation with the past and her becoming a writer are coded in Ulitskaya's text by two of the poems of the Zhivago cycle Winter Night and August and also in the related episodes of Pasternak's novel. All of these have biographical relevance and present creation as a fundamental element of life, which is closely linked to love and death as well as metaphysical experience. The symbolic parallel of this in Zhivago's August is the transfiguration of Jesus and "the light without a flame" that blinds the disciples. This symbolism appears in Jacob's Ladder on two levels: first, in the stage set that Nora creates for King Lear, and second, as a concomitant of her confrontation with the past and her becoming a writer.

It is in this way that the fundamental elements of Pasternak's life and poetry play a crucial role at the level of microstructures: they provide the context and symbolism of the central question of Ulitskaya's novel, the nature of "the essence" of the human.

Keywords: L. Ulitskaya, Jacob's Ladder, B. Pasternak, Doctor Zhivago, the transfiguration of Jesus, Zhivago poems, a light without a flame, King Lear

Open Access. This is an open-access article distributed under the terms of the Creative Commons Attribution 4.0 International License (https:/creativecommons.org/licenses/ by/4.0), which permits unrestricted use, distribution, and reproduction in any medium, provided the original author and source are credited, a link to the CC License is provided, and changes - if any - are indicated. (SID_1) 